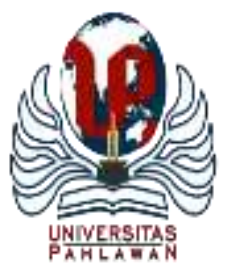

Edukatif : Jurnal Ilmu Pendidikan Volume 4 Nomor 1 Tahun 2022 Halm 1134 - 1139 EDUKATIF: JURNAL ILMU PENDIDIKAN

Research \& Learning in Education

https://edukatif.org/index.php/edukatif/index

\title{
Kebijakan Merdeka Belajar Kampus Merdeka: Pemahaman Persespsi dan Kendala Implementasinya bagi Mahasiswa Disabilitas
}

\author{
Yoga Budhi Santoso ${ }^{1 凶}$, Eka Yuli Astuti ${ }^{2}$, Agus Mulyanto ${ }^{3}$, Lilis Suandari ${ }^{4}$ \\ Universitas Islam Nusantara, Indonesia ${ }^{1,2,3,4}$ \\ E-mail :yogabudhisantoso@ uninus.ac.id ${ }^{1}$, ekayuliastuti@ uninus.ac.id ${ }^{2}$, agusmulyanto@ $\underline{\text { uninus.ac.id }}^{3}$, \\ lilissuawandari@uninus.ac.id ${ }^{4}$
}

\begin{abstract}
Abstrak
Berkembangnya pendidikan inklusif secara nasional di perguruan tinggi menjadi pendorong bagi pemerintah untuk menyediakan kebijaan yang ramah untuk semua, termasuk bagi mahasiswa disabilitas. Progam Merdeka Belajar Kampus Merdeka memberikan kesempatan untuk belajar di luar kampus melalui program yang beragam. Tujuannya adalah dapat mengakomodasi keberagaman potensi dan hambatan mahasiswa sehingga dapat dikembangkan untuk mencapai kompetensi yang sesuai dengan potensi dan bakatnya. Penelitian ini adalah penelitian kualitatif deskriptif yang bertujuan untuk mengetahui bagaimana implementasi kebijakan MBKM di tingkat prodi bagi mahasiswa diabilitas dan persepsi mahasiswa disabilitas terkait implementasi kebijakan tersebut. Penelitian ini menggunakan metode survey dengan total sampling yang melibatkan 29 mahasiswa diabilitas yang terdiri dari 20 mahaiswa tunanetra, 8 tunarungu dan 1 tunadaksa. Hasil penelitian menunjukkan bahwa terdapat pemahaman dan persepsi yang beragam dari mahasiswa disabilitas mengenai kebijakan MBKM dan terdapat prosentasi yang tinggi dari mahasiswa disabilitas yang belum memahami kebijakan ini. Kendala utama yang dihadapi dalam mengikuti program MBKM adalah kesulitan adapatasi terhadap lingkungan baru yang belum memberikan aksesibilitas dalam hal fisik dan sosial serta hambatan komunikasi.
\end{abstract}

Kata Kunci: Merdeka Belajar Kampus Merdeka, pendidikan inklusif, disabilitas.

\section{Abstract}

At the national level, the government support inclusive education and provide policies for implementation inclusive and friendly education for all in higher education, including for students with disabilities. The Program "Merdeka Belajar Kampus Merdeka (MBKM)" provides opportunities for students to experinces study outside the campus through various programs. The purpose is to accommodate the diversity of student's potentials and barriers, so that they can be developed to achieve competencies that are in accordance with their potential and talents. This research is a qualitative research that aims to find out how the implementation of the MBKM policies at the Special Education Departement, especially for students with disabilities and to find out the perceptions of students with disabilities related to the implementation of the policy. This study used a survey method with a total sampling involving 29 students with disabilities consisting of 20 blind students, 8 deaf students and a student with physical barriers. The results showed that there were various understandings and perceptions of students with disabilities regarding the MBKM policy and there was a high percentage of students with disabilities who did not understand this policy. The main obstacle faced in participating in the MBKM program is the difficulty of adapting to a new environment that does not provide physical and social accessibility and also there are communication barriers.

Keywords: Merdeka Belajar Kampus Merdeka, inclusive education, disabilities.

Copyright (c) 2022 Yoga Budhi Santoso, Eka Yuli Astuti, Agus Mulyanto, Lilis Suandari

$\triangle$ Corresponding author

Email : yogabudhisantoso@uninus.ac.id

DOI : https://doi.org/10.31004/edukatif.v4i1.2056 ISSN 2656-8071 (Media Online) 
1135 Kebijakan Merdeka Belajar Kampus Merdeka: Pemahaman Persespsi dan Kendala Implementasinya bagi Mahasiswa Disabilitas - Yoga Budhi Santoso, Eka Yuli Astuti, Agus Mulyanto, Lilis Suandari

DOI: https://doi.org/10.31004/edukatif.v4i1.2056

\section{PENDAHULUAN}

Pendidikan inklusif merupakan filosofi dan praktik pendidikan berkualitas tinggi yang bertujuan untuk pemenuhan kebutuhan peserta didik, dengan meningkatkan parsisipasi aktif semua siswa secara penuh (Messiou et al. 2016). Dalam pendidikan inklusif semua siswa diperlakukan seperti anggota sekolah yang berharga (Moriña 2017). Pendidikan inklusif sudah dikembangkan dan dimplementasikan dalam pendidikan dasar, dan menengah jauh sebelum di perguruan tinggi, dan telah berkembang menjadi sebuah gerakan yang menantang setiap eklusifitas (López Gavira and Moriña 2015); (Moriña 2017).

Universitas memiliki peranan penting dalam ningkatkan kualitas hidup masyarakat dan berkonstribusi dalam mengurangi diskriminasi sosial (Lipka, Forkosh Baruch, and Meer 2019), termasuk bagi individu dengan disabilitas. Bagi penyandang disabilitas, universitas dapat dianggap sebagai salah satu kendaraan yang dapat digunakan untuk meningkatkan kualitas hidup dan menghadirkan pengalaman-pengalaman yang penting bagi mereka (Järkestig Berggren et al. 2016). Saat ini banyak yang menyerukan peningkatan inklusivitas di dalam universitas, dan memandang bahwa universitas harus bertanggung jawab untuk menanggapi kebutuhan semua mahasiswa (Doughty and Allan 2008). Hal ini mendorong prinsip dan praktik inklusif masuk ke dalam agenda universitas, baik dalam kebijakan, dan praktik belajar-mengajar (Moriña 2017).

Walau banyak litaratur menunjukkan banyak upaya yang dilakukan universitas dalam membuat peraturan-peraturan yang menjamin hak-hak mahasiswa disabilitas (Moriña, Sandoval, and Carnerero 2020) namun implementasi pendidikan inklusif di pendidikan tinggi menunjukkan adanya praktik yang kurang tepat dan mahasiswa dengan diabilitas harus menghadapi berbagai hambatan (Love et al. 2015). Sejumlah besar literatur mengidentifikasi hambatan signifikan dalam partisipasi, kemajuan, dan keberhasilan mahasiswa diabilitas (Fernie and Henning 2006) bahkan angka drop-out pada kelompok ini masih tinggi (Veitch, Strehlow, and Boyd 2018); (Gibson 2015) dengan jumlah yang beragam (Moriña et al. 2020). Kurikulum yang tidak aksesibel, sikap negatif di antara fakultas dan staf menjadi beberapa pennyebabnya (Fernie and Henning 2006); (Oliver and Barnes 2010). Walau demikian, pendidikan inklusif di tinggkat perndidikan tinggi harus tetap diperjuangkan, hal ini dikarenakan inklusif adalah sebuah proses (Landers and Weaver 1997), proses dimana kita mencari cara terbaik untuk berespon terhadap keberagaman.

Berkembangnya norma dan peraturan yang mengakui hak-hak disabilitas (Hockings, Brett, and Terentjevs 2012) menjadi salah satu faktor yang mendorong banyak Institusi pendidikan tinggi mulai menerima mahasiswa dari berbagai latar belakang dan juga mahasiswa dengan penyandang disabilitas di kelas reguler (Beyene, Mekonnen, and Giannoumis 2020), termasuk di Indonesia. Melalui Permenristekdikti 46 Tahun 2017 tentang Pendidikan Khusus dan Pendidikan Layanan Khusus di Perguruan Tinggi, pemerintah Indonesia mendorong perguruan tinggi untuk menerima mahasiswa berkebutuhan khsusu termasuk di dalamnya mahasiswa dengan disabilitas dengan menekankan budaya inklusif. Walau peraturan ini baru terbit di tahun 2017, Progam Studi Pendikan Luar Biasa Universitas Islam Nusantara, telah menerima mahasiswa disabilitas sejak tahun 1983.

Pada tahun 2020, Menteri Pendidikan dan Kebudayaan Repubik Indonesia, mengeluarkan kebijakan Merdeka Belajar-Kampus Merdeka (MBKM). Kebijakan ini ditujukan untuk mendorong mahasiswa agar dapat menguasai berbagai keilmuan yang berguna untuk memasuki dunia kerja. Melaui Permendikbud Nomor 3 Tahun 2020 tentang Standar Nasional Pendidikan Tinggi, Perguruan Tinggi wajib memberikan hak bagi mahasiswa untuk dapat mengambil perkuliahan pada program studi yang berbeda di perguran tinggi tempat mahaiswa belajar sebanyak 1 semester (setara dengan 20 SKS), dan di luar perguruan tinggi sebanyak 2 semester (setara dengan 40 SKS). Pembelajaran di luar peguruan tinggi dapat berupa pertukaran pelajar, mangang/praktik kerja, asistensi mengajar, penelitian, proyek kemanusiaan, kegiatan wirausaha, studi/proyek idependen, dan membanun desa atau atau Kuliah Kerja Nyata Tematik (KKNT). 
1136 Kebijakan Merdeka Belajar Kampus Merdeka: Pemahaman Persespsi dan Kendala Implementasinya bagi Mahasiswa Disabilitas - Yoga Budhi Santoso, Eka Yuli Astuti, Agus Mulyanto, Lilis Suandari

DOI: https://doi.org/10.31004/edukatif.v4i1.2056

Beragamnya pilihan pembelajaran di luar kampus memberikan ruang yang luas bagi para mahasiswa untuk memilih aktivitas pembelajaran sesuai dengan potensi dan minat mereka. Kebijakan MBKM, seharusnya dapat menjadi peluang bagi mahasiswa disabilitas untuk dapat menembangkan potensi mereka sesuai dengan hambatan yang mereka miliki, namun apakah mahasiswa disabilitas pun memiliki persepsi yang sama? Penelitian ini ditujukan untuk melihat implementasi kebijakan Merdeka Belajar-Kampus Merdeka di tingkat program studi, khusunya bagi mahasiswa dengan disabilitas.

\section{METODE PENELITIAN}

Penelitian ini adalah penelitian kualitatif deskriptif yang dirancang guna mengetahui implementasi MBKM di tingkat progam studi dengan fokus pada mengetahui sejauh mana pengetahuan mahasiswa disabilitas mengenai kebijakan MBKM, progam yang paling diminiati, kesiapan mahasiswa dalam mengikuti program MBKM, persepsi mahasiswa terkait program MBKM dan dampak implementasi program. Penelitian melibatkan seluruh mahasiswa dengan diabilitas yang terdaftar di progam studi pendidikan luar biasa Universitas Islam Nusantara pada semua angkatan. Total partisipan 29 mahasiswa diabilitas yang terdiri dari 20 mahasiswa tunanetra, 8 mahasiswa tunarungu dan 1 orang mahasiswa tunadaksa. Penelitian ini mengguanakan metode survey mengeunakan google form dengan total sampling. Instumen survey berfokus pada aspek Analisis data mengunakan analisis data kualitatif dengan menggunakan tiga tahap yaitu reduksi data, display data dan penarian kesimpulan.

\section{HASIL DAN PEMBAHASAN PENELITIAN}

Berdasarkan hasil survey yang telah dilakukan sekitar 58.62\% mahasiswa hanya mengetahui sedikit mengenai kebijakan MBKM dan masih ada $17.24 \%$ yang tidak mengetahui mengenai adanya kebijakan ini. Mayoritas mahasiswa diabilitas, atau sekitar $48.28 \%$ mendapatkan informasi mengenai kebijakan MBKM melalui Kanal daring perguruan tinggi (laman/website, media sosial). Menurut survey lanjutan, minimnya pemahaman mereka dua hal utama yaitu bagi mahsiswa dengan tunanetra yaitu sekitar $35 \%$ mahasiswa kesulitan tunatra menyatakan memiliki hambatan untuk mengakses informasi dan mendapatkan informasi yang lengkap. Hal ini sangat dimungkinkan kareana penyandang tunanera memiliki kendala terkait mendapatan informasi berbasis teknologi dan info grafis jika mereka memiliki kendala dalam menggunakan teknologi (Douglas et al. 2011) ditambah dengan masih ada web yang tidak asesibel bagi penyandang tunanetra. Bagi mahasiswa tunarungu sekitar $87,5 \%$ memiliki hambatan dalam memahami maksud kebijakan tersebut. Kendala bahasa nampaknya menjadi salah satu faktor utama bagi mahasiswa tunarungu dalam memahami berbagai informasi mengenai kebijakan MBKM, hal ini dikebanyakan individu dengan tunarungu memiliki kemampuan bahasa yang lebih rendah dari teman-teman seuianya (Schirmer 1994); (Marschark and Knoors 2012).

Dari delapan progam pembelajaran di luar peguruan tinggi yang dapat diambil oleh mahaiswa, terdapat tiga program yang paling diminati oleh mayoritas mahasiswa diabilitasi yaitu program asistensi mengajar di satuan pendidikan $62.07 \%$, magang/praktik kerja sekitar $41.38 \%$ mahasiswa yang memilih, dan pertukaran pelajar sebesar $37.93 \%$. 
1137 Kebijakan Merdeka Belajar Kampus Merdeka: Pemahaman Persespsi dan Kendala Implementasinya bagi Mahasiswa Disabilitas - Yoga Budhi Santoso, Eka Yuli Astuti, Agus Mulyanto, Lilis Suandari

DOI: https://doi.org/10.31004/edukatif.v4i1.2056

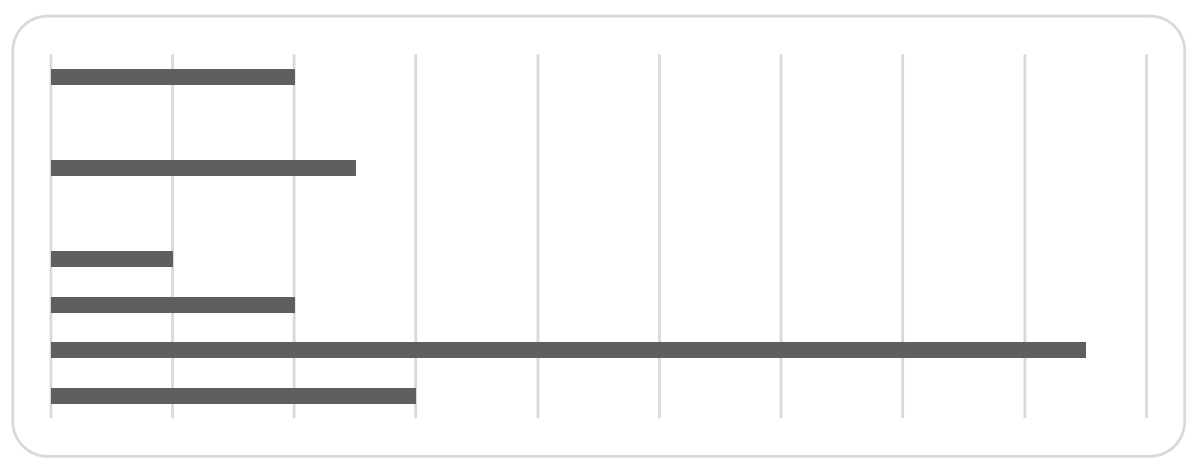

Gambar 1: Progam MBKM Pilihan Mahasiswa

Progam asistensi megajar pada satuan pendidikan dan magang/praktik kerja saat ini sudah bisa terfasilitasi dikarekanakan cukup banyak sekolah dan lembaga layanan terapi, lembaga penyedia guru pendamping khsus yang telah berkerjasama dengan progam studi, namun untuk pertukaran pelajar saat ini masih belum bisa terlaksana terutama untuk pertukaran kerjasama dengan program studi sejenis, meningat baru ada satu prodi yang telah menjalin kerjasama namun terkendala karena jarak yang sangat jauh.

Terkait dengan kesiapan mahasiswa disabilitas untuk mengikuti progam MBKM, terdapat 24,14\% yang sudah siap yang terdiri dari seluruh mahasiswa dengan hambatan tunarungu dan tuna daksa, sedangkan dari 55,17\% mahasiswa masih belum siap, memilih 20,69\% memilih opsi tidak tahu, semunya adalah mahasiwa dengan hambatan tunarungu.

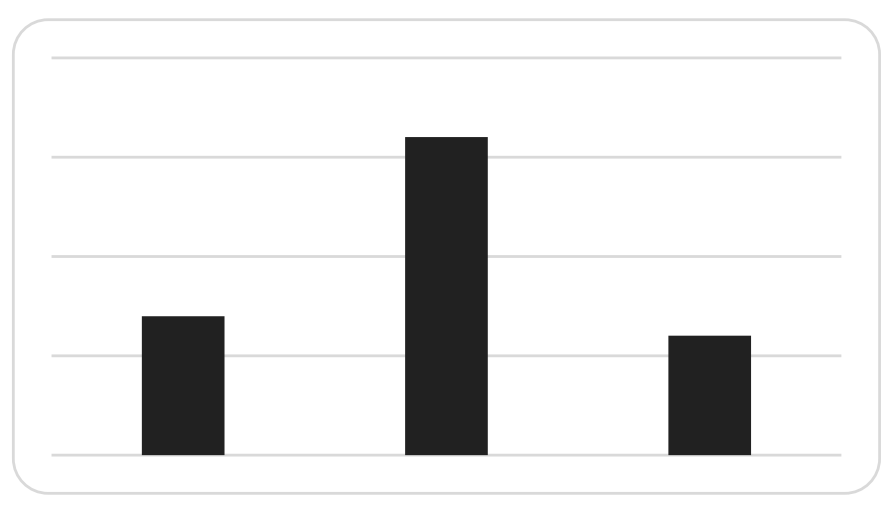

Gambar 2: Kesiapan Mahasiwa Disabilitas dalam Mengikuti Program MBKM

Berdasarkan hasil survey menunjukkan bahwa semua mahasiswa tunarungu masih belum siap mengikuti progam MBKM, Hal ini mungkin dikarenakan karena masih minimnya pemahaman mahasiswa dengan tunarungu terkait dengan kebijakan MBKM.

Pada aspek persepsi mahasiswa diabilitas mengenai dampak impementasi program MBKM pada program studi pendidikan luar biasa Uninus, diperloleh data bahwa $62.07 \%$ tidak mengetahui implikasinya, $20,69 \%$ mahasiswa mengangap bahwa progam ini akan membuat masa studi menjadi lebih lama dan 17,24\% anak membuat mereka tidak bisa lulus tepat waktu. Walau demikian mahasiswa mayoritas mahasiswa lebih dari 50\% mahasiwa mempercayai jika progam MBKM ini bermanfaat dan akan berdampak pada bertambahnya kompetensi dan perspektif mereka.

Berdasarkan survey lanjutan mengenai hambatan apa yang mungkin dihadapi oleh mahaiswa disabilitas dalam mengikuti progam MBKM, diperoleh jawaban yang beragam. Bagi mahasiswa tunarungu dan tunadasa sulit berdaptasi dengan lingkungan baru (baik dari kondisi sosial maupun aksesibilas) menjadi hambatan 
1138 Kebijakan Merdeka Belajar Kampus Merdeka: Pemahaman Persespsi dan Kendala Implementasinya bagi Mahasiswa Disabilitas - Yoga Budhi Santoso, Eka Yuli Astuti, Agus Mulyanto, Lilis Suandari

DOI: https://doi.org/10.31004/edukatif.v4i1.2056

utama bagi mereka. Hal ini terjadi karena memang penyandang tunarungu memiliki hambatan dalam orientasi dan mobilitas yang akhirnya membutuhan waktu yang lebih lama untuk menyesuaikan dalam lingkungan baru (Salive et al. 1994); (Swenor, Munoz, and West 2013). Bagi mahasiswa tunarungu ketidak pahaman yang utuh akan program MBKM, dan masalah kemampuan komunikasi (kesulitan untuk menggunakan bahasa oral, dan memahami pembicaraan orang lain) mereka menjadi hal yang dikhawatirkan dapat menghambat mereka dalam mengikuti program MBKM. Kemampuan komunikasi individu dengan tunarungu yang sangat beragam dan cara jug acara komunikasinya (Stinson et al. 1996), menjadi hal yang dapat menjadi faktor penghabat mereka ketika saat berada pada komunitas atau situasi yang baru.

\section{KESIMPULAN}

Berdasarkan hasil penelitian yang dilakukan dapat disimpulkan bahwa masih banyak mahasiswa disabilitas yang belum memahami dan memiliki persepsi yang kurang tepat dalam progam MBKM yang dijalankan di Program studi Pendidikan Luar Biasa Uninus. Terlihat dari bersarnya presentase mahasiswa yang masih belum memahami kebijakan ini dan anggapan mahasiswa yang kurang tepat sehingga melihat program ini akan memperpanjang waktu masa studi dan membuat tidak tepat waktu dalam menyelesaikan perkuliahan. Terdapat hambatan utama yang dikhawa oleh mahasiswa diabilitas untuk mengikuti program ini yaitu kehawatiran dalma penyesuian diri dengan lingkungan baru dan kemungkinan adanya perbedaan kondisi lingungan fisik, bahasa dan juga sosial. Berdasarkan kondisi tersebut maka program studi harus menyusun rencana yang lebih baik terkait dengan sosilaisasi progam MBKM yang lebih baik dengan mempertimbangkan setiap hambatan yang dimiliki oleh mahasiswa disabilitas. Progam sosialisasi MBKM yang ramah bagi diabilitas harus menjadi prioritas bagi prodi ke depan agar kebijakan ini dapat diimplementasikan secara optimal.

\section{DAFTAR PUSTAKA}

Beyene, Wondwossen Mulualem, Abraham Tulu Mekonnen, And George Anthony Giannoumis. 2020. "Inclusion, Access, And Accessibility Of Educational Resources In Higher Education Institutions: Exploring The Ethiopian Context." International Journal Of Inclusive Education 1-17.

Doughty, Hannah, And Julie Allan. 2008. "Social Capital And The Evaluation Of Inclusiveness In Scottish Further Education Colleges." Journal Of Further And Higher Education 32(3):275-84.

Douglas, Graeme, Mike Mclinden, Steve Mccall, Sue Pavey, Jean Ware, And Ann Marie Farrell. 2011. "Access To Print Literacy For Children And Young People With Visual Impairment: Findings From A Review Of Literature." European Journal Of Special Needs Education 26(1):25-38.

Fernie, Todd, And Marcus Henning. 2006. "From A Disabling World To A New Vision." Pp. 41-49 In Towards Inclusive Learning In Higher Education. Routledge.

Gibson, Suanne. 2015. "When Rights Are Not Enough: What Is? Moving Towards New Pedagogy For Inclusive Education Within UK Universities." International Journal Of Inclusive Education 19(8):87586.

Hockings, Christine, Paul Brett, And Mat Terentjevs. 2012. "Making A Difference-Inclusive Learning And Teaching In Higher Education Through Open Educational Resources.” Distance Education 33(2):23752.

Järkestig Berggren, Ulrika, Diana Rowan, Ewa Bergbäck, And Barbro Blomberg. 2016. "Disabled Students' Experiences Of Higher Education In Sweden, The Czech Republic, And The United States-A Comparative Institutional Analysis." Disability \& Society 31(3):339-56.

Landers, Mary F., And H. Roberta Weaver. 1997. Inclusive Education: A Process, Not A Placement. ERIC. 
1139 Kebijakan Merdeka Belajar Kampus Merdeka: Pemahaman Persespsi dan Kendala Implementasinya bagi Mahasiswa Disabilitas - Yoga Budhi Santoso, Eka Yuli Astuti, Agus Mulyanto, Lilis Suandari

DOI: https://doi.org/10.31004/edukatif.v4i1.2056

Lipka, Orly, Alona Forkosh Baruch, And Yael Meer. 2019. "Academic Support Model For Post-Secondary School Students With Learning Disabilities: Student And Instructor Perceptions." International Journal Of Inclusive Education 23(2):142-57.

López Gavira, Rosario, And Anabel Moriña. 2015. "Hidden Voices In Higher Education: Inclusive Policies And Practices In Social Science And Law Classrooms." International Journal Of Inclusive Education 19(4):365-78.

Love, Tyler S., Nicole Kreiser, Elsa Camargo, Michael E. Grubbs, Eujin Julia Kim, Penny L. Burge, And Steven M. Culver. 2015. "STEM Faculty Experiences With Students With Disabilities At A Land Grant Institution." Journal Of Education And Training Studies 3(1):27-38.

Marschark, Marc, And Harry Knoors. 2012. "Educating Deaf Children: Language, Cognition, And Learning." Deafness \& Education International 14(3):136-60.

Messiou, Kyriaki, Mel Ainscow, Gerardo Echeita, Sue Goldrick, Max Hope, Isabel Paes, Marta Sandoval, Cecilia Simon, And Teresa Vitorino. 2016. "Learning From Differences: A Strategy For Teacher Development In Respect To Student Diversity." School Effectiveness And School Improvement 27(1):45-61.

Moriña, Anabel. 2017. "Inclusive Education In Higher Education: Challenges And Opportunities." European Journal Of Special Needs Education 32(1):3-17.

Moriña, Anabel, Marta Sandoval, And Fuensanta Carnerero. 2020. "Higher Education Inclusivity: When The Disability Enriches The University." Higher Education Research \& Development 39(6):1202-16.

Oliver, Mike, And Colin Barnes. 2010. "Disability Studies, Disabled People And The Struggle For Inclusion." British Journal Of Sociology Of Education 31(5):547-60.

Salive, Marcel E., Jack Guralnik, Robert J. Glynn, William Christen, Robert B. Wallace, And Adrian M. Ostfeld. 1994. "Association Of Visual Impairment With Mobility And Physical Function." Journal Of The American Geriatrics Society 42(3):287-92.

Schirmer, Barbara R. 1994. Language And Literacy Development In Children Who Are Deaf. ERIC.

Stinson, Michael, Yufang Liu, Rosemary Saur, And Gary Long. 1996. "Deaf College Students' Perceptions Of Communication In Mainstream Classes." The Journal Of Deaf Studies And Deaf Education 1(1):40 51.

Swenor, Bonnielin K., Beatriz Munoz, And Sheila K. West. 2013. "Does Visual Impairment Affect Mobility Over Time? The Salisbury Eye Evaluation Study." Investigative Ophthalmology \& Visual Science 54(12):7683-90.

Veitch, Sarah, Karin Strehlow, And James Boyd. 2018. "Supporting University Students With Socially Challenging Behaviours Through Professional Development For Teaching Staff." Journal Of Academic Language And Learning 12(1). 